systems are smaller than the ion-molecule encounter frequencies by a factor of about $10^{-8 \pm 1}$. Thus, minute traces of impurities might scavenge the charges and the identities of the ions responsible for the radiation induced conductance in the purified hydrocarbons would be difficult to establish with certainty. Some confidence may be placed, however, in the values of $G\left(\operatorname{esc} e^{-}\right)$obtained from the solutions of ion scavengers (Table II). It is not known whether the solutes scavenged both or only one of the types of charge, but an average of all the values of $G$ (esc $\left.e^{-}\right)$obtained from the two assumptions should give a value within $50 \%$ of the true one. The average, with the mean deviation, of all 20 values of $G\left(\right.$ esc $\left.e^{-}\right)$for cyclohexane given in Table II is $0.20 \pm 0.03$.

\section{General Discussion}

Magee $^{25}$ has suggested that the free ions in irradiated condensed systems are a result of the ability of the moderate energy secondary electrons, or delta rays, to

${ }_{25}$ J. L. Magee, Ann. Rev. Phys. Chem. 12, 389 (1961). escape from their parent ions. He calculated $G$ (delta ray) $\approx 0.1$ for a system irradiated with fast charged particles. This idea has been extended by doing a numerical and graphical analysis of delta-ray spectra to determine the energy below which secondary electrons fail to escape from their parent ions. The average energy of the primary electrons generated by $\mathrm{Co}^{60}$ gamma rays is $590 \mathrm{keV}$. The delta-ray spectra for primary electrons with energies 192 and $384 \mathrm{keV}^{26}$ were analyzed, and the results were extrapolated to 590 $\mathrm{keV}$. If it were assumed that each delta-ray with energy greater than $100 \mathrm{eV}$ resulted in one ion pair, the value $G\left(\operatorname{esc} e^{-}\right)=0.06$ would be calculated for $590-\mathrm{keV}$ electrons. By extrapolating the delta-ray spectra to lower energies with a semilogarithmic plot, it was determined that, to obtain a value $G\left(\operatorname{esc} e^{-}\right)=0.20$, it was necessary to assume that each delta-ray with energy greater than 30 or $40 \mathrm{eV}$ resulted in one ion pair.

${ }^{26}$ D. E. Lea, Actions of Radiations on Living Cells (Cambridge University Press, Cambridge, England, 1955), 2nd ed., Tables 15 and 16, pp. 28-29.

\title{
Photochemical Studies in Flash Photolysis. III. Photolysis of Acetone in Different Wavelength Regions*
}

\author{
A. ShILman and R. A. Marcos $\dagger$ \\ Department of Chemistry, Polytechnic Institute of Brooklyn, Brooklyn, New York
}

(Received 29 June 1962)

\begin{abstract}
The flash photolysis of acetone was studied at wavelength regions centered around 260,280 , and $300 \mathrm{~m} \mu$, using absorbed intensities of the order of $10^{19}$ quanta/cc/sec for each wavelength region. The light source was an exploding wire, and the maximum temperature increase per flash was calculated to be not more than $5^{\circ} \mathrm{C}$. The products, analyzed by gas chromatography using a sensitive electric discharge detector, consisted of $\mathrm{C}_{2} \mathrm{H}_{6}, \mathrm{CO}$, biacetyl, and, in smaller amounts, $\mathrm{CH}_{4}$. A search was made for other products as well, and detection limits are given.

The $\mathrm{C}_{2} \mathrm{H}_{6} / \mathrm{CO}$ ratio decreased with increasing acetone pressure at all wavelength regions and was independent of light intensity in the range investigated. The $R_{\mathrm{CO}} / p_{\mathrm{acet}}$ ratio, measured over a wide pressure range, was pressure-independent at 260 and $300 \mathrm{~m} \mu$ but increased appreciably with pressure at $280 \mathrm{~m} \mu$. At low pressures, where the $\mathrm{C}_{2} \mathrm{H}_{6} / \mathrm{CO}$ ratio approached a limiting value, the ratio decreased with wavelength according to the order $280>260>300 \mathrm{~m} \mu$.

The lifetime of the excited acetone molecules at the respective wavelengths was estimated, from a steadystate treatment, to be $0.6 \times 10^{-9}, 1 \times 10^{-9}$, and $4 \times 10^{-9} \mathrm{sec}$ at 260,280 , and $300 \mathrm{~m} \mu$, assuming a collision deactivation efficiency of unity. At $300 \mathrm{~m} \mu$ there was a marked difference in value of $\mathrm{C}_{2} \mathrm{H}_{6} / \mathrm{CO}$ at flash and low intensities: certain second-order reactions involving excited states appear to occur completely at the relatively high concentrations prevailing under flash conditions. The transition region of intensity effects is described in subsequent papers of this series.
\end{abstract}

\section{INTRODUCTION}

W HILE acetone photolysis has been the subject of extensive investigation at low intensities ${ }^{1,2}$, only a

* Abstracted in part from the doctoral dissertation of Avner Shilman, Polytechnic Institute of Brooklyn, June 1961. (Available on microfilm from University Microfilms, Ann Arbor, Michigan.) This work was supported by the Directorate of Chemical Sciences,

Air Force Office of Scientific Research.

+ Alfred P. Sloan Fellow.

1 Cf. review by E. W. R. Steacie, Alomic and Free Radical

Reactions (Reinhold Publishing Corporation, New York, 1954.)

${ }^{2}$ Cf. review by W. A. Noyes, G. B. Porter, and J. E. Jolley, Chem. Rev. 56, 49 (1956). few studies have been made at the extremely high intensities of flash photolysis ${ }^{3-6}$ or of spark discharge. ${ }^{7}$ Under flash conditions the data are freed from complications of first-order thermal reactions and diffusion

${ }^{3}$ M. A. Kahn, R. G. W. Norrish, and G. Porter, Proc. Roy. Soc. (London) A219, 312 (1953).

${ }_{4}^{4}$ G. K. Oster and R. A. Marcus, J. Chem. Phys. 27, 472 (1957)

(Part I).

${ }^{B}$ N. Slagg and R. A. Marcus, J. Chem. Phys. 34, 1013 (1961)

(Part II).

6 G. Wettermark, Arkiv. Kemi 18, 1 (1961).

${ }^{7}$ J. L. Roebber, G. K. Rollefson, and G. C. Pimentel, J. Am. Chem. Soc. 80, 255 (1958). 


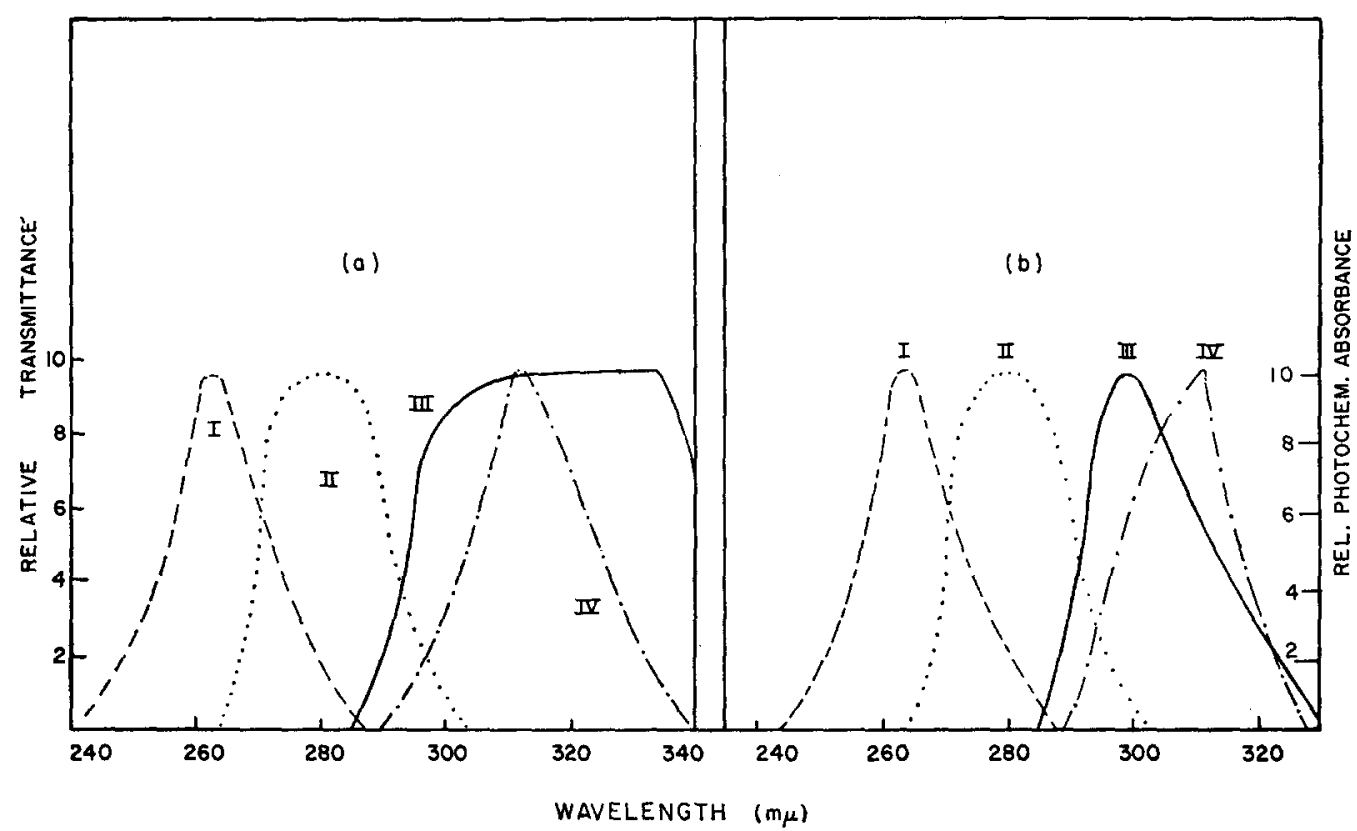

FIG. 1. Spectral characteristics of the filtered light at various wavelengths: (a) radiation transmitted by filters, (b) photochemically effective absorbance. Spectra were obtained by placing immediately in front of the spectrograph two quartz cells, each of $1 \mathrm{~cm}$ path length and having parallel optically flat faces. The first contained a $\mathrm{NiSO}_{4}-\mathrm{CoSO}_{4}$ solution $(40 \mathrm{~g}$ of each in $100 \mathrm{cc}$ water) and the second contained one of the following: (I) 1,4-diphenylbutadiene in alcohol (25 mg/liter), (II) $\mathrm{CS}_{2}$ in $\mathrm{CCl}_{4}$ (4.65 g/liter), (III) single layer of duPont cellophane 88-CA-48, (IV) $\mathrm{K}_{2} \mathrm{CrO}_{4} 0.2 M$, $\mathrm{KHPh} 0.05 M$, $\mathrm{NaOH} 0.05 M$ in water. Relative peak values in (a) are: (I) 0.75 , (II) 0.94 , (III) 0.66 , (IV) 1.00 , and in (b) : (I) 0.71 , (II) 1.00 , (III) 0.57 , (IV) 0.22 .

to walls, though they are not without other problems. Unfortunately, most flash intensity studies of the acetone and of other systems have been made in a broad region of the spectrum. Moreover, the analysis for the photolysis products was not complete, except in one case, ${ }^{6}$ where the radiation contained appreciable contributions from wavelengths below $200 \mathrm{~m} \mu$.

In the present studies, pressure and intensity effects were studied in four regions of the spectrum, namely, at wavelengths centered around $260,280,300$, and $310 \mathrm{~m} \mu$. Since the results in the last two regions were somewhat similar to each other, only one of them, $300 \mathrm{~m} \mu$, was investigated extensively. The analysis for the photolysis products was performed with a gas chromatography unit specifically designed for that purpose.

\section{EXPERIMENTAL}

\section{Apparatus}

The apparatus consisted of three main units: (1) the vacuum system where samples were prepared for the photolysis experiments, for analysis and for the calibration of the gas-chromatography apparatus. (The reaction vessel consisted of a Vycor tube $3.0 \mathrm{~cm}$ o.d. and $16 \mathrm{~cm}$ long rounded at one end, after being reduced at the other end to $1 \mathrm{~cm}$ o.d. and attached to a joint through a graded seal. The total cell volume was $94 \mathrm{cc}$, of which $85 \mathrm{cc}$ were illuminated.) (2) the flash apparatus previously described, ${ }^{8}$ (3) the gas chromatography unit employing silica gel, molecular sieve 5A and P.E.G. columns, and a very sensitive electric discharge detector. ${ }^{9}$ The molecular sieve required careful preconditioning (heating and passing gases through column) to attain marked improvement of sensitivity for $\mathrm{CO}^{. \mathrm{b}}$

\section{Materials}

Acetone (99 mole \%, Fisher) was purified to remove traces of the possible photolysis products by first treating it with silver nitrate and sodium hydroxide solutions. ${ }^{10}$ It was then dried over anhydrous magnesium sulfate and distilled in vacuo from $-78^{\circ}$ to $-196^{\circ} \mathrm{C}$. The middle fraction was stored at $-78^{\circ} \mathrm{C}$. The purification procedure for the rest of the materials was the same as in Part I.

\section{Filters}

The radiation which was emitted by the exploding nichrome wire consisted of numerous nickel and chromium lines and so was almost continuous throughout the absorption region of acetone. To isolate wavelength regions centered around $260,280,300$, and $310 \mathrm{~m} \mu$, a solution of 1,4-diphenyl butadiene in ethanol, ${ }^{6,11}$ one of $\mathrm{CS}_{2}$ in $\mathrm{CCl}_{4},{ }^{5}$ a single layer of $88-\mathrm{CA}-48$ du Pont

(a) R. C. Pitkethly, paper presented before the 132nd meeting of the American Chemical Society, New York, September 1957. The construction used in this paper is rather similar and is described in Ref. 9(b). (b) A. Shilman, Ph.D. thesis, Polytechnic Institute of Brooklyn, June 1961.

${ }^{10} \mathrm{~A}$. Vogel, Practical Organic Chemistry (Longmans Green and Company, Ltd., London, 1954).

${ }^{11}$ M. Kasha, J. Opt. Soc. Am. 38, 929 (1948). 
TABLE I. Flash photolysis of acetone. Pressure effects at wavelengths near $260 \mathrm{~m} \mu{ }^{\mathrm{a}}$

\begin{tabular}{|c|c|c|c|c|c|c|}
\hline Expt. & $\begin{array}{l}P_{\mathrm{soet}} \\
(\mathrm{mm})\end{array}$ & No. of flashes & $\begin{array}{c}\mathrm{CO} \times 10^{10} / P_{\mathrm{acet}} \\
(\mathrm{moles} / \mathrm{flash} / \mathrm{mm})\end{array}$ & $\mathrm{C}_{2} \mathrm{H}_{6} / \mathrm{CO}$ & $\left(\mathrm{CH}_{3} \mathrm{CO}\right)_{2} / \mathrm{CO}$ & $\mathrm{CH}_{4} / \mathrm{CO}$ \\
\hline 27 & 26.4 & 20 & 0.73 & 3.2 & $1.4(?)$ & 0.25 \\
\hline 28 & 74 & 8 & 0.62 & 3.3 & 2.1 & $\cdots$ \\
\hline$\cdots$ & $100^{b}$ & $\cdots$ & $\cdots$ & 2.7 & $\cdots$ & $0.1 \mathrm{~g}$ \\
\hline 29 & 150 & 4 & 0.57 & 2.5 & 1.4 & $0.1_{8}$ \\
\hline$\cdots$ & $200^{b}$ & $\cdots$ & $\cdots$ & 1.9 & $\cdots$ & 0.10 \\
\hline 30 & 242 & 4 & 0.77 & 1.8 & $\cdots$ & 0.05 \\
\hline \multirow[t]{2}{*}{33} & 200 & 4 & $(0.33)^{\circ}$ & 1.9 & $\cdots$ & 0.05 \\
\hline & $+747 \mathrm{~mm} \mathrm{CO}_{2}$ & & & & & \\
\hline
\end{tabular}

A cetaldehyde was not present in the product above $2 \%$ of biacetyl yield in Expts. 27,28 , and 29. Methyl ethyl ketone was not present in the product above $50 \%$ and $100 \%$ of methane yield in Expts. 27 and 29 respectively, and not above $15 \%$ of CO yield at $74 \mathrm{~mm}$. The wire was $3.25 \mathrm{~cm}$ from center of reaction vessel.

b Values at 100 and $200 \mathrm{~mm}$ taken from Ref. 5.

- Low value due to reduced intensity of flash. The degree of reduction in intensity was found to be 0.50 by using acetone vapor in unfiltered Vycor vessel as an actinometer.

Cellophane $e^{5}$ and a solution of potassium chromate, potassium acid phthalate, and sodium hydroxide in water, ${ }^{11}$ respectively, were used. Spectra of the light coming from the flash after passing through these filters were recorded on Kodak 33 plates using a medium quartz Hilger spectrograph. Tracings of these photographic plates were made with a Leeds and Northrup densitometer and are given in Fig. 1. These were multiplied by the absorption coefficients of acetone $\mathrm{e}^{12}$ to give a "photochemically effective absorbance" (Fig. 1).

\section{Actinometry}

The relative intensities of radiation were determined with a ferrioxalate actinometer ${ }^{13}$ contained in a Vycor vessel identical with the reaction vessel.

\section{Procedure}

After the required amount of gas was admitted to the reaction vessel, it was detached, secured on the flash apparatus and surrounded by the filter contained in a 5-cm-i.d. Vycor jacket concentric with the 3-cm-0.d.

TABLE II. Flash photolysis of acetone. Pressure effects at wavelengths near $280 \mathrm{~m} \mu$. $^{\circ}$

\begin{tabular}{|c|c|c|c|c|c|c|}
\hline Expt. & $\begin{array}{l}P_{\mathrm{aoet}} \\
(\mathrm{mm})\end{array}$ & No. of flashes & $\begin{array}{c}\mathrm{CO} \times 10^{10} / P_{\text {acet }} \\
(\mathrm{moles} / \mathrm{flash} / \mathrm{mm})\end{array}$ & $\mathrm{C}_{2} \mathrm{H}_{6} / \mathrm{CO}$ & $\left(\mathrm{CH}_{3} \mathrm{CO}\right)_{2} / \mathrm{CO}$ & $\mathrm{CH}_{4} / \mathrm{CO}$ \\
\hline 21 & 4.1 & 28 & 1.05 & 5.3 & 4.9 & 0.18 \\
\hline 20 & 9.0 & 20 & 1.18 & 5.9 & ... & 0.18 \\
\hline 23 & 25.4 & 8 & 1.37 & 5.3 & 4.0 & $\cdots$ \\
\hline 22 & 50 & 4 & 1.70 & 4.6 & 3.2 & 0.15 \\
\hline 25 & 75 & 2 & 1.87 & 3.5 & ... & $\cdots$ \\
\hline 24 & 75 & 8 & 1.86 & 3.5 & 2.3 & 0.15 \\
\hline 12 & 100 & 4 & 2.17 & 2.2 & 1.2 & ... \\
\hline 26 & 201 & 4 & 2.20 & 1.4 & 0.4 & 0.15 \\
\hline 31 & 243 & 4 & 2.70 & 1.4 & 0.4 & 0.07 \\
\hline \multirow[t]{2}{*}{32} & 200 & 4 & $(1.40)^{\mathrm{b}}$ & 1.1 & ... & 0.07 \\
\hline & $+747 \mathrm{~mm} \mathrm{CO}$ & & & & & \\
\hline
\end{tabular}

a Actaldehyde was not present in the product above $2 \%$ of biacetyl yield in Expts. 12, 21-24, 26, and 31. Methyl ethyl ketone was not present in the product above $15 \%, 25 \%, 60 \%$, and $100 \%$ of methane yield in Expts. 21, 24, 26, and 31 respectively, and not above $10 \%$ of CO yield in Expt. 23. The wire was 3.25 cm from center of reaction vessel.

b Low value due to reduced intensity of flash. The degree of reduction in intensity was found to be 0.50 by using acetone vapor in unfiltered Vycor vessel as an actinometer.

${ }^{12}$ C. W. Porter and C. Iddings, J. Am. Chem. Soc. 48, 40 (1926).

13 C. A. Parker, Proc. Roy. Soc. (London) A220, 104 (1953); cf. A235, 518 (1956). 
TABIE III. Flash photolysis of acetone. Pressure effects at wavelengths near $300 \mathrm{~m} \mu$.*

\begin{tabular}{|c|c|c|c|c|c|c|}
\hline Expt. & $\begin{array}{l}P_{\text {aeet }} \\
(\mathrm{mm})\end{array}$ & No. of flashes & $\begin{array}{c}\mathrm{CO} \times 10^{10} / P_{\text {acet }} \\
(\mathrm{moles} / \mathrm{flash} / \mathrm{mm})\end{array}$ & $\mathrm{C}_{2} \mathrm{H}_{6} / \mathrm{CO}$ & $\left(\mathrm{CH}_{3} \mathrm{CO}\right)_{2} / \mathrm{CO}$ & $\mathrm{CH}_{4} / \mathrm{CO}$ \\
\hline 19 & 3.6 & 28 & 2.7 & 1.9 & 0.8 & ... \\
\hline 14 & 9.7 & 20 & 3.0 & 1.8 & 0.8 & $0.1_{3}$ \\
\hline 18 & 16.4 & 12 & 2.8 & 1.5 & 0.5 & $0.1_{4}$ \\
\hline 15 & 23.3 & 8 & 2.9 & 1.2 & 0.2 & $0.1_{s}$ \\
\hline 17 & 26.7 & 8 & 2.9 & 1.1 & $\ldots$ & 0.09 \\
\hline 16 & 48.8 & 4 & 2.8 & 1.2 & $\ldots$ & $0.1_{5}$ \\
\hline 11 & 101 & 4 & 2.9 & 1.1 & $\cdots$ & $0.2_{4}$ \\
\hline$P 6^{\mathrm{b}}$ & 52 & 4 & 0.56 & 1.1 & $\cdots$ & $\cdots$ \\
\hline$P 7^{\mathrm{b}}$ & 51 & 4 & 0.61 & 1.2 & $\cdots$ & $\ldots$ \\
\hline$P 8^{\mathrm{b}}$ & 50 & 1 & 4.6 & 1.1 & $\ldots$ & $\ldots$ \\
\hline
\end{tabular}

a Acetaldehyde was not present in the product above $10 \%$ of biacetyl yield in Expts. 14, 15, 18, and 19, and not above $2 \%$ of CO yield in Expts. 11 and 17. Methyl ethyl ketone was not present in the product above $10 \%, 25 \%$, and $30 \%$ of methane yield in Expts. 14, 17, and 11. Except in Expts. P6 to P8, the wire was $3.25 \mathrm{~cm}$ from center of reaction vessel.

b In Expt. $P 8$, the wire was $2 \mathrm{~cm}$ from the axis of the reaction vessel. In Expts. $P 6$ and $P 7$, the wire was $8 \mathrm{~cm}$ distant and the vessel was surrounded both by the filter used on the other experiments of this Table and by a $8.3 \mathrm{~cm}$ i.d. Vycor cylinder containing NiSO4-CoSO4 solution (40 $\mathrm{g}$ of each in $100 \mathrm{cc}$ water). The effective light path of the latter solution was $1.3 \mathrm{~cm}$.

reaction vessel. A Nichrome wire, $18 \mathrm{~cm}$ long, was then placed parallel to the axis of the reaction vessel at the specified distance. The 33- $\mu \mathrm{F}$ bank of condensers of the flash apparatus was then charged to $8000 \mathrm{~V}$ and then discharged through the exploding wire to ground. After the required number of flashes the reaction vessel was attached to the vacuum system where $75 \%$ of its contents were transferred into a bulb by expansion, diluted with nitrogen to atmospheric pressure, and analyzed by gas chromatography.

A record of the light output vs time was obtained by placing a $935 \mathrm{RCA}$ phototube some distance $(1 \mathrm{~m})$ from the exploding wire to minimize electrical effects and photographing the trace appearing on a calibrated oscilloscope. The trace is given in Fig. 2.14

\section{RESULTS}

$\mathrm{CO}, \mathrm{C}_{2} \mathrm{H}_{6}, \mathrm{CH}_{4}$, and, in many cases, biacetyl were the products measured. A search was also made for possible

Frg. 2. Trace of

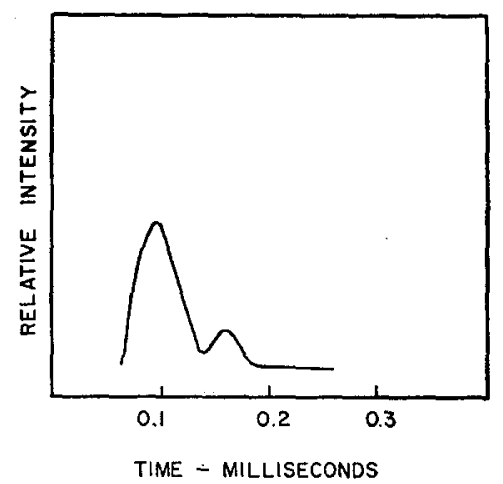

${ }^{14}$ We are indebted to $\mathrm{J}$. Knoll of this laboratory for Fig. 2. formation of $\mathrm{CH}_{3} \mathrm{CHO}$ and $\mathrm{CH}_{3} \mathrm{COC}_{2} \mathrm{H}_{5}$. The results obtained on pressure and light intensity effects in the various wavelength regions are described in Tables $\mathrm{I}-\mathrm{V}$ and Figs. 3-6. The wavelength effects on the $\mathrm{C}_{2} \mathrm{H}_{6} / \mathrm{CO}$ ratio vs acetone pressure curve may be compared with the corresponding plot where only radiation below 220 $\mathrm{m} \mu$ is removed (Fig. 6; results not tabulated).

\section{SUMMARY OF RESULTS}

A review of the results of acetone photolysis at different wavelengths, given in Tables I-V, Figs. 3-6, yields the following information:

(1) The only reaction products found were carbon monoxide, ethane, biacetyl, and methane. Within experimental error, the amount of biacetyl was equal to

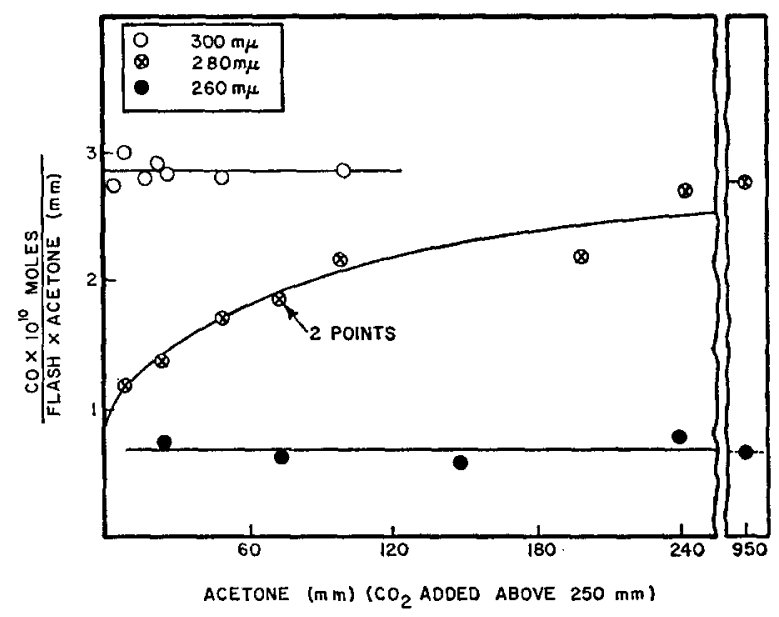

FIG. 3. Variation of $\mathrm{CO}$ yield with pressure at different wavelengths. 
TABLE IV. Flash photolysis of acetone. Pressure effects at wavelengths near $310 \mathrm{~m} \mu$. $^{\mathrm{s}}$

\begin{tabular}{|c|c|c|c|c|c|c|}
\hline Expt. & $\begin{array}{c}P_{\text {acot }} \\
(\mathrm{mm})\end{array}$ & No. of flashes & $\begin{array}{c}\mathrm{CO} \times 10^{10} / P_{\text {acet }} \\
(\mathrm{moles} / \mathrm{flash} / \mathrm{mm})\end{array}$ & $\mathrm{C}_{2} \mathrm{H}_{6} / \mathrm{CO}$ & $\left(\mathrm{CH}_{3} \mathrm{CO}\right)_{2} / \mathrm{CO}$ & $\mathrm{CH}_{4} / \mathrm{CO}$ \\
\hline 38 & 15.6 & 24 & 1.07 & 1.4 & 0.4 & 0.14 \\
\hline 37 & 50 & 8 & 1.10 & 1.1 & $\cdots$ & 0.15 \\
\hline$P 9^{\mathrm{b}}$ & 50 & 10 & 0.22 & 1.1 & $\cdots$ & $\cdots$ \\
\hline$P 12^{\mathrm{e}}$ & 51 & 7 & 0.23 & 1.1 & $\cdots$ & $\cdots$ \\
\hline$P 17^{\mathrm{d}}$ & 51 & 40 & 0.028 & 1.1 & $\cdots$ & $\cdots$ \\
\hline
\end{tabular}

Acetaldehyde was not present in the product above $6 \%$ of biacetyl yield in Expt. 38 and not above $3 \%$ of CO yield in Expt. 37 . Methyl ethyl ketone was not present above $20 \%$ of methane yield in Expt. 38 and not above $50 \%$ in Expt. 37 . In Expts. 37 and 38 , the wire was $3.25 \mathrm{~cm}$ from center of reaction vessel. In Expt. $P 9$ it was $8 \mathrm{~cm}$.

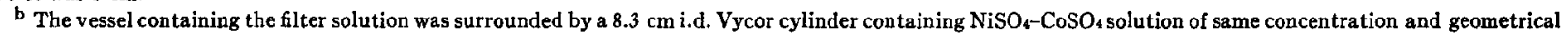
arrangement as in Table III for Expts. $P 6$ and P7.

- duPont Cellophane 88-CA-48 was wrapped around a reaction vessel placed in a 5.3-cm-o.d. Pyrex cylinder, which in turn was surrounded by an 8.3-cm i.d. Vycor jacket containing $\mathrm{NiSO}_{4}-\mathrm{COSO}_{4}$ solution of same concentration as in Expts. P6, P7, and P9. The effective light path through the solution was $1.5 \mathrm{~cm}$. The distance of the wire from the reaction vessel was $8 \mathrm{~cm}$. The photochemical absorption of the resulting system consisted of wavelengths near $305 \mathrm{~m} \mu$ and half-width $20 \mathrm{~m} \mu$ (width at half intensity).

d The reaction vessel was placed immediately behind a $2 \times 15-\mathrm{cm}$ plate, $3-\mathrm{mm}$ Corning Glass $7-60$, which was covered on the side exposed to the exploding wire by duPont Cellophane 215 P.D. The distance from the wire to the axis of the reaction vessel was $5 \mathrm{~cm}$. The photochemical absorption of this system involved wavelengths near $323 \mathrm{~m} \mu$ and halfwidth $10 \mathrm{~m} \mu$.

the amount of ethane less that of carbon monoxide (Tables I-IV).

(2) Methyl ethyl ketone was not found in amounts of more than $50 \%$ of a minor product, methane, at low pressures of acetone. At still lower pressures the corresponding figure is $10 \%-20 \%$. (Tables I-IV).

(3) Acetaldehyde was not present in amounts of more than $10 \%$ of the amount of biacetyl. At lower pressures the corresponding figure is $5 \%$ (Tables I-IV).

(4) The quantum yield of carbon monoxide was not dependent on acetone pressure except at $280 \mathrm{~m} \mu$ (Table II, Fig. 3), where it increased with increasing acetone pressure (Table II, Fig. 3).

(5) The $\mathrm{C}_{2} \mathrm{H}_{6} / \mathrm{CO}$ and biacetyl/CO ratios decreased with increasing acetone pressure at all wavelengths (Tables I-IV, Fig. 4).

(6) The $\mathrm{C}_{2} \mathrm{H}_{6} / \mathrm{CO}$ ratio at $260 \mathrm{~m} \mu$ (Table I, Fig. 4)

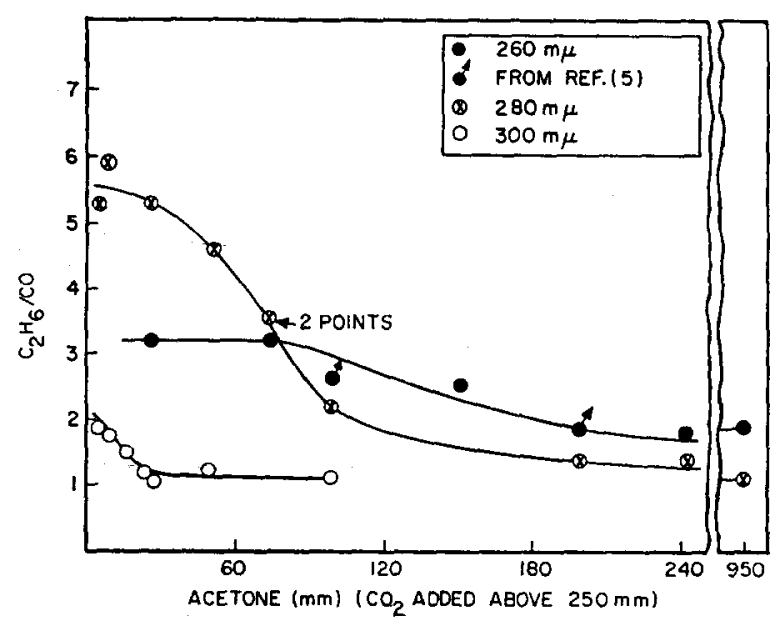

Fig. 4. Variation of $\mathrm{C}_{2} \mathrm{H}_{6} / \mathrm{CO}$ ratio with pressure at different wavelengths. was not reduced to unity even at $1000 \mathrm{~mm}$ pressure of added carbon dioxide and acetone. At all other waveleng ths this ratio did reduce to unity at higher pressures.

(7) The $\mathrm{C}_{2} \mathrm{H}_{6} / \mathrm{CO}$ ratio approached at low acetone pressures limiting values which decreased with wavelength according to the order $280>260>300 \mathrm{~m} \mu$ (Fig. 4).

(8) The quantum yields of carbon monoxide, ethane and biacetyl (from mass balance) did not change when the incident light intensity was changed by a factor of 5 at all wavelengths (Table V).

(9) Methane was a minor product (Tables I-IV). The $\mathrm{CH}_{4} / \mathrm{CO}$ ratios were essentially constant within the rather large experimental error of the methane analysis. The trend for these ratios, at higher pressures to increase at $300 \mathrm{~m} \mu$ and to decrease at 260 and $280 \mathrm{~m} \mu$ is uncertain due to insufficient data at these pressures.

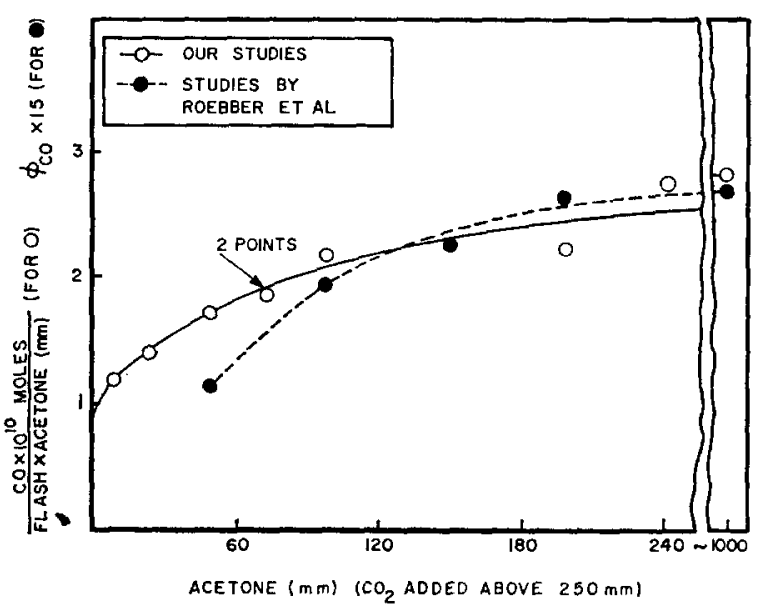

FIG. 5. Comparison of CO yield at $280 \mathrm{~m} \mu$ with data of Roebber et $a l^{7}$ 
TABLE V. Flash photolysis of acetone. Intensity effects at various wavelengths.

\begin{tabular}{|c|c|c|c|c|c|c|}
\hline Expt. & $\begin{array}{l}\text { Distance of wire } \\
(\mathrm{cm})\end{array}$ & $\begin{array}{l}\text { Relatives } \\
\text { intensity }\end{array}$ & $\begin{array}{l}\text { Wavelength } \\
\qquad(\mathrm{m} \mu)\end{array}$ & $\begin{array}{c}\mathrm{CO} \times 10^{10} / P_{\text {acet }} \\
\text { (moles } / \text { flash } / \mathrm{mm})\end{array}$ & $\mathrm{C}_{2} \mathrm{H}_{6} / \mathrm{CO}$ & Relative $\phi_{C O}{ }^{b}$ \\
\hline 39 & 3.25 & & 300 & 2.9 & 1.4 & \\
\hline 40 & 16.3 & 0.17 & 300 & 0.51 & 1.4 & 1.05 \\
\hline 41 & 3.25 & & 280 & 1.86 & 3.4 & \\
\hline 42 & 16.3 & 0.18 & 280 & 0.36 & 3.5 & 1.02 \\
\hline 44 & 3.25 & & 260 & 0.65 & 2.5 & \\
\hline 45 & 16.3 & 0.17 & 260 & 0.116 & 2.4 & 1.06 \\
\hline
\end{tabular}

Refers to amount of light absorbed at $16.3 \mathrm{~cm}$ relative to amount of light absorbed at $3.25 \mathrm{~cm}$, determined actinometrically. At 300 , 280 , and 260 m $\mu$, the acetone was 16,75 , and $150 \mathrm{~mm}$, respectively, corresponding in each case to the critical pressure regions of Fig. 4.

b This column represents the CO quantum yield at $16.3 \mathrm{~cm}$ distance relative to $C O$ quantum yield at $3.25 \mathrm{~cm}$.

(10) The $\mathrm{C}_{2} \mathrm{H}_{6} / \mathrm{CO}$ and $\mathrm{CH}_{4} / \mathrm{CO}$ ratios obtained at wavelengths centered around $310 \mathrm{~m} \mu$ were similar to the corresponding ratios in the $300 \mathrm{~m} \mu$ wavelength region (Tables III and IV).

(11) The $\mathrm{C}_{2} \mathrm{H}_{6} / \mathrm{CO}$ ratio at $300 \mathrm{~m} \mu$ was much lower than that obtained at low (nonflash) light intensities, being 1.1 to 1.2 at $50 \mathrm{~mm}$ acetone instead of $1.7^{15}$ to $1.9,{ }^{16}$ and much lower than that obtained with very low flash intensities. ${ }^{17}$ Detailed experiments were described in Part IV ${ }^{17}$ where the flash intensity was lowered by as much as a factor of $10^{4}$ and the transition region for change of value of $\mathrm{C}_{2} \mathrm{H}_{6} / \mathrm{CO}$ was located. Similar differences were not found at $260 \mathrm{~m} \mu$ however, at the flash intensities equal to or less than those used in this paper. ${ }^{18}$

(12) The drop in $\mathrm{C}_{2} \mathrm{H}_{6} / \mathrm{CO}$ ratio at $300 \mathrm{~m} \mu$ mentioned in No. 11 is due largely or entirely to a change in quantum yield of $\mathrm{CO}$ formation. . $^{17,18}$

(13) The independence of the carbon monoxide and ethane quantum yields of light intensity suggests that any temperature changes occurring during the flash were relatively small or, if appreciable, were without effect on the yield. Indeed, because of the low flash intensities used, as a result of using filters, the expected

$15 \mathrm{~J}$. Heicklen and W. A. Noyes, Jr., J. Am. Chem. Soc. 81, 3858 (1959). These authors used a BTH medium-pressure lamp with a Pyrex- $\mathrm{NiSO}_{4}$-CoSO 4 -Corning 9863 filter. The intensity was such that the $C O$ production rate per unit illuminated volume was about $10^{-13} \mathrm{~mole}^{-1} \mathrm{sec}^{-1}$. The percent conversion of acetone to biacetyl was of the order of $0.01 \%$, the importance of small conversions having been shown by these authors.

${ }_{16}$ In unpublished results we have used an AH 6 lamp with the same filter as that used in Ref. 15 and, in other experiments, with the filter used in the present paper (to make the absorbed light wavelength distribution approximate that of the flash photolysis system at $300 \mathrm{~m} \mu$ ). The intensity corresponded to a $\mathrm{CO}$ production rate per unit reaction volume of $10^{-12}$ mole cc-1 $\sec ^{-1}$ and the percent conversion to biacetyl was of the order of $0.01 \%$. The corresponding figures for the flash system in the experiments labeled $P$ in Tables III and IV are: $\mathrm{CO}$ production $=$ $10^{-6} \mathrm{~mole} / \mathrm{cc} / \mathrm{sec}$ and percent conversion of acetone actually illuminated $=0.01 \%$.

${ }_{17}$ A. Shilman and R. A. Marcus, Bull. Soc. Chim. Belges 71, 653 (1962).

18 A. Shilman and R. A. Marcus (unpublished results, presented at the Photochemistry Symposium, Rochester, New York, 27-29 March 1963). Results are currently being obtained at $280 \mathrm{m \mu}$. rise in temperature can be calculated to be less than $5^{\circ} \mathrm{C}^{19}$

\section{DISCUSSION OF $\mathrm{CH}_{3} \mathrm{CO}$ AND CO FORMATION}

Throughout the discussion we note that only secondorder reactions of the radicals need be considered, except where the radicals are "hot," since the competitive processes which are first order in radical concentration are too slow (e.g., Part II). These competitive processes are primarily hydrogen-atom abstraction from acetone by methyls, unimolecular decay of acetyls, and diffusion to the walls of either.

Considering first the behavior at $300 \mathrm{~m} \mu$, where the $\mathrm{C}_{2} \mathrm{H}_{6} / \mathrm{CO}$ ratio is much less when high flash intensities are used, one interpretation of the above data is the following: (A denotes acetone, $A_{1}$ and $A_{2}$ being two different excited states).

$$
\begin{gathered}
\mathrm{A}+\mathrm{h} \nu \longrightarrow \mathrm{A}_{1}^{*}, \\
2 \mathrm{~A}_{1}{ }^{*} \longrightarrow 2 \mathrm{CH}_{3}+\mathrm{CO}+\mathrm{A}, \\
\stackrel{\text { decay }}{\longrightarrow} \mathrm{A}, \\
\mathrm{A}+\mathrm{h} \nu \longrightarrow \mathrm{A}_{2}^{*}, \\
\mathrm{~A}_{2}{ }^{*} \longrightarrow \mathrm{CH}_{3} \mathrm{CO}+\mathrm{CH}_{3}, \\
\mathrm{M}+\mathrm{A}_{2}{ }^{*} \longrightarrow \mathrm{M}+\mathrm{A}, \\
\mathrm{A}+\mathrm{h} \nu \quad \rightarrow 2 \mathrm{CH}_{3}+\mathrm{CO},
\end{gathered}
$$

where "decay" in (3) means phosphorescence and

${ }^{19}$ At 260 and $280 \mathrm{~m} \mu$ at $50 \mathrm{~mm}$ pressure, $\phi_{\mathrm{CO}}$ is $0.2^{20}$ and $0.05,{ }^{7}$ respectively, and $R_{\mathrm{CO}}$ is $3 \times 10^{-9}$ and $8.5 \times 10^{-0} \mathrm{~mole} / \mathrm{flash}$, respectively. Using a $C_{v}$ value of $16 \mathrm{cal} / \mathrm{mole}$ for acetone, ${ }^{21}$ the temperature rise is computed to be less than $1^{\circ} \mathrm{C}$ at both wavelengths. At $300 \mathrm{~m} \mu$ and $16 \mathrm{~mm}$ pressure, the incident radiation was determined by actinometry to be $5.1 \times 10^{-5}$ einsteins. The molar extinction coefficient of acetone at $300 \mathrm{m \mu}$ is 7.03 liter/ $\mathrm{mole} / \mathrm{cm} .{ }^{12}$ Employing the above $C_{v}$ the temperature rise is calculated to be $5^{\circ} \mathrm{C}$. This value is a maximum due to the photochemical geometry, for refraction effects would cause the amount of light entering the liquid actinometer to exceed that entering acetone vapor in a similar vessel.

${ }_{20}$ D. S. Herr and W. A. Noyes, Jr, J. Am. Chem. Soc. 62, 2052 (1940).

${ }_{21}$ R. E. Pennington and K. A. Kobe, J. Am. Chem. Soc. 79, 305 (1957). 


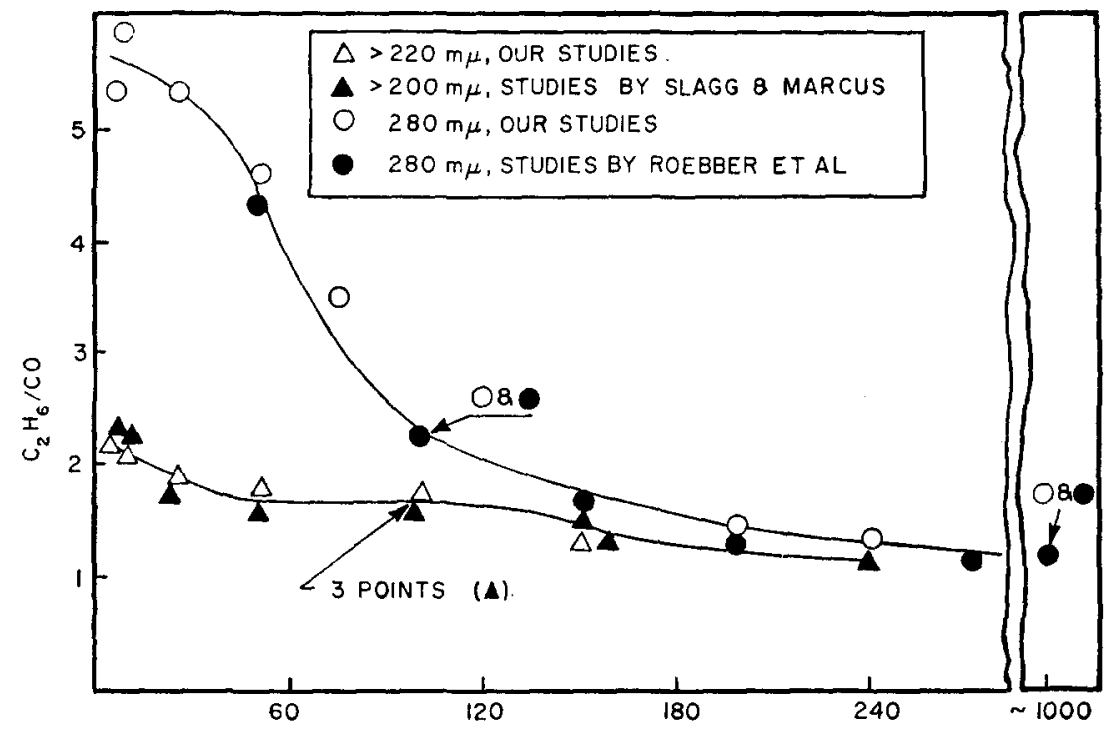

FIG. 6. Comparison of $\mathrm{C}_{2} \mathrm{H}_{6} / \mathrm{CO}$ ratios of different investigations.

ACETONE (MM) $\left(\mathrm{CO}_{2}\right.$ ADDED ABOVE $\left.275 \mathrm{MM}\right)$

internal conversion, and where the intermediate in (7) could be $A_{1}{ }^{*}, A_{2}{ }^{*}$, etc. (Projected experiments at low flash intensities should establish its nature). At high flash intensities at $300 \mathrm{~m} \mu$, however, (2) must swamp (7), according to the data. ${ }^{22}$

A major feature of the interpretation is that at high flash intensities (and conceivably at low), two unconnected mechanisms for $\mathrm{CO}$ and $\mathrm{CH}_{3} \mathrm{CO}$ production at $300 \mathrm{~m} \mu$ are introduced. The mechanisms were taken to be unconnected to explain two facts:

(i) $\phi_{\left(\mathrm{CH}_{3} \mathrm{CO}\right)_{2}}$ and the estimated ${ }^{17} \phi_{\mathrm{CH}_{3} \mathrm{CO}}$ appear to be essentially constant over an intensity variation of at least a factor of $10^{2}$, but $\phi_{\mathrm{CO}}$ is appreciably increased (by a factor of 4) from one limiting value at low flash intensities to another one at high flash intensities. ${ }^{17,18}$

(ii) At high flash intensities $\phi_{\mathrm{CO}}$ is pressure independent but $\phi_{\left(\mathrm{CH}_{3} \mathrm{CO}\right)_{2}}$ is not.

The mechanism (1) to (7) is consistent with the fact that the quantum yields at high flash intensities are independent of intensity, that $\phi_{\mathrm{CO}}$ is independent of acetone pressure, and that $\phi_{\mathrm{C}_{2} \mathrm{H}_{6}}$ decreases with pressure. Moreover, long-lived excited acetone molecules, with a lifetime of $2 \times 10^{-4} \mathrm{sec}$, have been detected at $300 \mathrm{m \mu}$, ${ }^{23}$ and one may calculate that under the flash conditions used here Reaction (2) is at least a possibility. ${ }^{24}$ Phos-

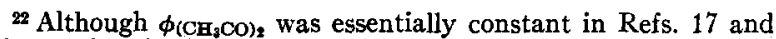
18 over the wide intensity variation, $\phi$ co increased by a factor of 4 .

${ }^{23}$ W. E. Kaskan and A. B. F. Duncan, J. Chem. Phys. 18, 427 (1950)

${ }^{24}$ At the highest flash intensity and at $50 \mathrm{~mm}$ acetone, the $\mathrm{CO}$ production which should be roughly one-half that of $\mathrm{A}_{1}{ }^{*}$, according to Reaction 2 , was about $10^{-10}$ moles $/ \mathrm{cc} /$ flash. ${ }^{17}$ The transition region in $\mathrm{C}_{2} \mathrm{H}_{0} / \mathrm{CO}$ ratio occurred at an intensity about 50 -fold less.17 Thus, if the collision frequency of excited molecules was about $10^{15} \mathrm{cc} / \mathrm{mole} / \mathrm{sec}$, an $A_{1}{ }^{*}$ in that region would make about $4 \times 10^{3}$ collisions/sec with ano ther $A_{1}{ }^{*}$. If the $A_{1}{ }^{*}$ had a natural decay rate constant given by the observed lifetime of the phosphorescent species, $2 \times 10^{-4} \mathrm{sec}$, namely $3.5 \times 10^{3} \mathrm{sec}^{-1}$ these two competitive fates for $A_{1}{ }^{*}$ would be of the same order magnitude in the transition region, assuming the above collision frequency. phorescence experiments by J. Knoll in this laboratory are now in progress at these flash intensities to see if, in fact, any correlation does exist between the quantum yields of $\mathrm{CO}$ production and phosphorescence. Evidence for a reaction similar to (2) has been obtained for excited biacetyl molecules under nonflash conditions. ${ }^{25}$

To explain the small residual $\phi_{\mathrm{CO}}$ at $300 \mathrm{~m} \mu$, found at very low flash intensities, ${ }^{18,26}$ Reaction (7) is postulated.

At $260 \mathrm{~m} \mu$, Fact No. 11 indicates that Reaction (2) does not occur at flash intensities equal to or less than those employed in this paper. Since the quantum yield of $\mathrm{CO}$ production at $260 \mathrm{~m} \mu$ was pressure-independent but that of biacetyl was not (Facts 4 and 5), the formation of $\mathrm{CO}$ and $\mathrm{CH}_{3} \mathrm{CO}$ appear to be unconnected, so we assume in Reaction (7) that the intermediate is not $A_{2}{ }^{*}$. Perhaps it is $A_{1}{ }^{*}$. At $260 \mathrm{~m} \mu$, part of biacetyl formation was not suppressed by increased pressure, although part was, suggesting that at this wavelength a portion of (5) occurs via a very short-lived molecule.

It has been suggested that a collision-induced dissociation occurs ${ }^{7}$ at $280 \mathrm{~m} \mu$ to form $\mathrm{CO}$ and we have no evidence against this postulate. Such a postulate offers one explanation for the increase of $\phi_{\mathrm{Co}}$ with increasing acetone pressure.

In the mechanism (1) to (7) at $300 \mathrm{~m} \mu$ we did not consider two alternative possibilities to Reaction (2): (i) $\mathrm{A}_{1}{ }^{*}+\mathrm{CH}_{3} \mathrm{CO} \rightarrow \mathrm{A}+\mathrm{CH}_{3}+\mathrm{CO}$ and (ii) $\mathrm{A}_{1} *+\mathrm{h} \nu \rightarrow$ $2 \mathrm{CH}_{3}+\mathrm{CO}$. The first possibility is excluded by the

\footnotetext{
${ }^{25}$ W. A. Noyes, Jr., W. A. Mulac and M. S. Matheson, J. Chem. Phys. 36, 880 (1962) and references cited.

${ }_{26}$ It may be noted that E. O'Neal and S. W. Benson found negligible $\mathrm{CO}$ when acetone was photolyzed in the presence of $\mathrm{HI}$, with steady illumination at $313 \mathrm{~m} \mu$ and $126^{\circ} \mathrm{C}$. [J. Chem. Phys. 36, 2196 (1962)]. In Ref. 18 the data at low flash intensities (no $\mathrm{HI}$ added) showed small but not negligible $\mathrm{CO}$. It is not yet known whether the difference of these two results arises from the different conditions or from possible deactivation of the pertinent $A^{*}$ by $\mathrm{HI}$.
} 
need for making the $\mathrm{CO}$ and $\mathrm{CH}_{3} \mathrm{CO}$ productions independent. The second possibility is very unlikely since the maximum pressure of $\mathrm{A}_{1}{ }^{*}$ in the $\mathrm{C}_{2} \mathrm{H}_{6} / \mathrm{CO}$ transition region can be estimated to be about $5 \times 10^{-4} \mathrm{~mm}$ at 50-mm acetone (cf. Ref. 24). Thus, the extinction coefficient of $A_{1}{ }^{*}$ would have to be unusually large for a. comparable decomposition to occur.

\section{Other Aspects}

If a steady-state treatment were assumed (not a strictly accurate assumption under these flash conditions but presumably sufficient for our purposes), the pressure effects in Fig. 4 indicate values for the lifetimes of the excited state $\mathrm{A}_{2}{ }^{*}$ of $0.6 \times 10^{-9}, 1 \times 10^{-9}$, and $4 \times$ $10^{-\theta} \mathrm{sec}$ at 260,280 and $300 \mathrm{~m} \mu$, respectively, assuming a frequency of successful deactivating collisions of $10^{14} \mathrm{cc}$ mole $^{-1} \mathrm{sec}^{-1}$ in Stern-Volmer plots [Figs. 14 and 15 of Ref. 9(b)].

The absence of acetaldehyde relative to biacetyl shows that the disproportionation reaction, postulated in earlier flash work ${ }^{7}$ at $280 \mathrm{~m} \mu, \mathrm{CH}_{3} \mathrm{CO}+\mathrm{CH}_{3} \mathrm{CO} \rightarrow$ $\mathrm{CH}_{3} \mathrm{CHO}+\mathrm{CH}_{2} \mathrm{CO}$, is unimportant relative to the recombination to form biacetyl.

The $\mathrm{CH}_{4}$ data are not sufficiently accurate to distinguish among mechanisms for $\mathrm{CH}_{4}$ formation.

\section{COMPARISON WITH PREVIOUS STUDIES}

Our studies are in agreement with the flash photolysis studies in Part II made at high acetone pressures and in the same wavelength regions.

Roebber et $a l^{7}$ have flash photolyzed acetone using a monochromatic light source ( $\mathrm{Mg}$ spark) at $280 \mathrm{~m} \mu$ at intensities similar to ours. They found no significant changes in the quantum yield of $\mathrm{CO}, \mathrm{C}_{2} \mathrm{H}_{6}$, and biacetyl when the light intensity was changed by a factor of 8 , nor when the duration of the discharge was increased by a factor of 17 (from 0.14 to $2.4 \mathrm{msec}$ ). In our work, where the flash duration was $0.1 \mathrm{msec}$ the quantum yields of $\mathrm{CO}$ and $\mathrm{C}_{2} \mathrm{H}_{6}$ were not changed when the incident light intensity was changed fivefold.

A comparison of the effects of acetone pressure observed by Roebber et al. ( 50 to $274 \mathrm{~mm}$ ) on the $\mathrm{CO}$ quantum yield and on the $\mathrm{C}_{2} \mathrm{H}_{6} / \mathrm{CO}$ ratio at $280 \mathrm{~m} \mu$ with those observed by us ( 4 to $243 \mathrm{~mm}$ ) in the same wavelength region is given in Figs. 5 and 6 . In their common range, the results of the two studies are very similar, with one exception, even though the light was monochromatic in Ref. 7 and contained a range of wavelengths in our case. The exception involves the low value of Ref. 7 for $\phi_{\mathrm{CO}}$ at their lowest pressure $(50 \mathrm{~mm})$. Roebber $e t$ al. extrapolated the $\phi_{\mathrm{CO}}$ plot to zero pressure, found the value zero and assumed that $\mathrm{CO}$ arose only from collision induced dissociation. Their extrapolation leaned heavily on the $50-\mathrm{mm}$ point and it would be desirable to extend their study to lower pressures.

Acetaldehyde, which was assumed, from mass balance considerations, to be present in the work of Ref. 7 to the extent of $10 \%-25 \%$ of biacetyl, was not found here in amounts greater than $2 \%$ (at $280 \mathrm{~m} \mu$ ) of the biacetyl yield.

In a recent study with the full spectrum of the flash which, as in Part I, showed major photochemical contributions from wavelengths below $200 \mathrm{~m} \mu$, Wettermark $^{6}$ made a very detailed analysis of the reaction products. He found hydrogen, methyl ethyl ketone and acetaldehyde in small amounts, in addition to the products found in this paper. Except at $280 \mathrm{~m} \mu$, where we took special pains in the analysis because of the work of Ref. 7, Wettermark's percent yields of acetaldehyde and methyl ethyl ketone were normally lower than our limits of detection.

Wettermark also made measurements ${ }^{6}$ of the ethane quantum yield as a function of acetone pressure, in a system where the radiation below $270 \mathrm{~m} \mu$ and above $380 \mathrm{~m} \mu$ was eliminated by a filter. He found it to decrease with increasing acetone pressure in a way similar to our $\mathrm{C}_{2} \mathrm{H}_{6} /$ (acetone) vs acetone pressure behavior at $280 \mathrm{~m} \mu$.

\section{ACKNOWLEDGMENTS}

This research was supported by the Directorate of Chemical Sciences Air Force Office of Scientific Research and by the Alfred P. Sloan Foundation. We greatly appreciate some useful comments by Dr. J. Heicklen. 